\title{
Gambaran Pengetahuan Remaja Putri Kelas Vii Tentang Menstruasi
}

\author{
Endriyani Martina Yunus*, Nandini Parahita Supraba \\ Poltekkes Kemenkes Pangkalpinang, Indonesia \\ Email Korespondensi: endriyani_my@yahoo.com
}

\begin{abstract}
Abstrak
Pengetahuan tentang menstruasi ini perlu diberikan sejak dini, karena dapat mempengaruhi perilaku seseorang dalam bertindak. Penelitian ini bertujuan mengetahui mengetahui Gambaran Pengetahuan Remaja Putri Kelas VII Tentang Menstruasi di SMP Negeri 10 Pangkalpinang tahun 2018. Jenis penelitian ini deskriptif, dengan menggunakan data primer.

Hasil penelitian dari 99 responden, diketahui bahwa 31 responden $(40,3 \%)$ pengetahuan tentang menstruasi dengan nilai baik, 37 responden $(48,1 \%)$ pengetahuan tentang siklus menstruasi dengan nilai kurang dan 51 responden $(66,2 \%)$ pengetahuan tentang gangguan menstruasi dengan nilai kurang.

Untuk meningkatkan pengetahuan siswa tentang menstruasi perlu peran dari guru khususnya pada mata pelajaran Biologi agar lebih menjelaskan tentang menstruasi, siklus menstruasi dan gangguan menstruasi.
\end{abstract}

Kata Kunci : menstruasi, siklus, gangguan

\section{The Description Of Adolescent Girls's Knowledge About Menstruation}

\begin{abstract}
Knowledge of menstruation needs to be given early, because it can affect one's behavior in acting. This study aims to find out to know "The Description of Adolescent Girls's Knowledge about menstruation at junior high school in Pangkalpinang in the year 2018. This type of research is descriptive, using primary data.

The results of the study of 99 respondents, it is known that 31 respondents $(40.3 \%)$ knowledge about menstruation with good grades, 37 respondents $(48.1 \%)$ knowledge of the menstrual cycle with less value and 51 respondents $(66.2 \%)$ knowledge about disorders menstruation with less value.

To increase students' knowledge about menstruation, the role of the teacher, especially in Biology subjects, needs to be better explained about menstruation, menstrual cycle and menstrual disorders.
\end{abstract}

Keywords : menstruation, cycle, disorder

\section{PENDAHULUAN}

Masa Remaja merupakan masa transisi yang terjadi dari masa anak-anak ke masa remaja. Individu mulai mengembangkan ciriciri abstrak dan konsep diri menjadi lebih berbeda. Remaja mempunyai sifat yang unik,salah satunya yaitu sifat ingin meniru sesuatu yang dilihat, kepada keadaan,serta lingkungan di sekitarnya. Remaja mempunyai kebutuhan akan kesehatan seksual, dimana pemenuhan kebutuhan seksual tersebut bervariasi (Kusmiran, 2012).
Pubertas yang dialami oleh remaja khususnya wanita yaitu ditandai dengan haid pertama kali atau menarche kemudian berlanjut dengan menstruasi (Atikah, 2009). Menstruasi merupakan perdarahan yang teratur dari uterus sebagai tanda bahwa organ kandungan telah berfungsi matang (Kusmiran, 2012).

Menstruasi merupakan siklus bulanan yang normal pada wanita. Siklus mentruasi biasanya dimulai pada wanita muda umur 1215 tahun (menarche) yang terus berlanjut sampai umur 45-50 tahun (menopause) 
tergantung pada berbagai faktor, termasuk kesehatan wanita, status nutrisi, dan berat tubuh relatif terhadap tinggi tubuh (Saryono, 2009).

Sindrom premenstruasi dapat mengganggu prestasi belajar siswi sehingga upaya penanganan dapat diperlukan untuk mengurangi gejala yang dirasakan. Upaya penaganan sindrom pramenstruasi dipengaruhi oleh faktor pengetahuan, sosial ekonomi, pendidikan, kondisi fisik, informasi dan maturitas. Pengetahuan sangat mempengaruhi seseorang dalam menentukan sikap terhadap suatu masalah. Pengetahuan siswi yang baru mendapat menstruasi ini pun bersifat umum hanya sebatas pengetahuan dari orang sekitar dan belum mencapai pemahaman. Sehingga banyak dari remaja yang tidak mengetahui dampak setelah mengalami menstruasi, seperti matangnya organ reproduksi, tingkat kesuburan dan secara seksual sudah siap untuk memiliki keturunan. Sehingga pentingnya pengetahuan dari orang tua dan pihak sekolah agar remaja lebih terarah (Atikah, 2009).

Mengingat pentingnya kesehatan reproduksi terutama bagi wanita pemerintah mengambil kebijakan teknis mengenai program kesehatan reproduksi meliputi : peningkatan promosi kesehatan reproduksi remaja, pengembangan KIE kesehatan remaja, peningkatan kegiatan konseling kepada remaja yang membutuhkan, meningkatkan dukungan bagi kesehatan yang positif (BKKBN, 2005).

\section{METODE PENELITIAN}

Jenis / desain penelitian ini adalah deskriptif, yaitu suatu metode penelitian yang dilakukan dengan tujuan untuk mendapatkan gambaran yang akurat dari sejumlah karakteristik masalah yang diteliti dan berguna untuk mendapatkan makna baru, menggambarkan kategori suatu masalah, menjelaskan frekuensi suatu kejadian dari sebuah fenomena

Tujuan penelitian ini untuk mengetahui mengetahui Gambaran Pengetahuan Remaja Putri Kelas VII Tentang Menstruasi di SMP Negeri 10 Pangkalpinang tahun 2018.

Manfaat penelitian ini diharapkan dapat menambah wawasan ilmu pengetahuan tentang menstruasi, siklus Menstruasi dan gangguan Menstruasi pada remaja putri dan merupakan salah satu upaya mencapai mensosialisasikan tentang menstruasi pada remaja putri.

\section{HASIL}

Tabel 1

Distribusi Pengetahuan Remaja

\begin{tabular}{lll}
\hline $\begin{array}{l}\text { Pengetahuan } \\
\text { Menstruasi }\end{array}$ & n & \% \\
\hline Kurang & 26 & 33,8 \\
Cukup & 20 & 26,0 \\
Baik & 31 & 40,3 \\
Total & 77 & 100 \\
\hline
\end{tabular}

Tabel 2

Distribusi Pengetahuan Siklus

\begin{tabular}{lcc}
\hline $\begin{array}{l}\text { Pengetahuan } \\
\text { Siklus }\end{array}$ & & \\
\hline Kurang & 37 & 48,1 \\
Cukup & 32 & 41,6 \\
Baik & 8 & 10,4 \\
Total & 77 & 100 \\
\hline
\end{tabular}

Tabel 3

Distribusi Pengetahuan Gangguan

Pengetahuan

Gangguan

\begin{tabular}{lcc}
\hline Kurang & 51 & 66,2 \\
Cukup & 24 & 31,2 \\
Baik & 2 & 2,6 \\
Total & 77 & 100 \\
\hline
\end{tabular}

Tabel 4

Distribusi Pekerjaan

\begin{tabular}{lll}
\hline Pekerjaan & & \\
\hline Tidak Bekerja & 89 & 89,9 \\
Bekerja & 10 & 10,1 \\
Total & 99 & 100 \\
\hline
\end{tabular}

Tabel 5

Distribusi Pengetahuan

\begin{tabular}{llc}
\hline Pengetahuan & & \\
\hline Baik & 37 & 37,4 \\
Cukup & 33 & 33,3 \\
Kurang & 29 & 29,3 \\
Total & 99 & 100 \\
\hline
\end{tabular}

Hasil ini menggambarkan distribusi frekuensi responden, diketahui bahwa 31 responden $(40,3 \%)$ pengetahuan tentang menstruasi dengan nilai baik, 37 responden 
$(48,1 \%)$ pengetahuan tentang siklus menstruasi dengan nilai kurang dan 51 responden $(66,2 \%)$ pengetahuan tentang gangguan menstruasi dengan nilai kurang.

\section{PEMBAHASAN}

Pengetahuan Tentang Menstruasi

Berdasarkan hasil penelitian didapatkan 31 responden $(40,3 \%)$ pengetahuan tentang menstruasi dengan nilai baik, ini dikarenakan siswa mendapatkan informasi tentang menstruasi dengan baik dan informasi tersebut dapat bersumber dari teman, orang tua, serta persepsi mereka sendiri walaupun belum dapat dipastikan kebenarannya. Untuk meningkatkan pengetahuan seseorang didapatkan dengan cara membaca buku tentang menstruasi, mendapatkan pengetahuan mengenai menstruasi dengan cara mengikuti penyuluhan tentang menstruasi. Menurut Notoatmodjo, 2003, peningkatan pengetahuan didapat melalui jalur formal, sedangkan jalur non formal dapat diperoleh melalui membaca, mendengarkan penyuluhan, media massa atau informasi dari orang tua, saudara dan teman.

Menurut Notoatmodjo, 2010, pengetahuan merupakan hasil dari tahu dan ini terjadi setelah seseorang melakukan penginderaan terhadap suatu objek tertentu. Sebagian besar pengetahuan manusia diperoleh melalui mata dan telinga (Notoatmodjo, 2010).

Pengetahuan Tentang Siklus Menstruasi

Berdasarkan hasil penelitian didapatkan 37 responden $(48,1 \%)$ pengetahuan tentang siklus menstruasi dengan nilai kurang. Pengetahuan tentang siklus menstruasi dapat diperoleh oleh siswa di dalam mata kuliah biologi yang membahas mengenai kesehatan reproduksi khususnya mengenai menstruasi.

Menurut Sunaryo (2007) menyebutkan pendidikan merupakan upaya memberikan pengetahuan, sehingga terjadi perubahan positif yang meningkat.

Pengetahuan Tentang Gangguan Menstruasi. Berdasarkan hasil penelitian menunjukan bahwa 51 responden $(66,2 \%)$ pengetahuan tentang gangguan menstruasi dengan nilai kurang. Menurut Lucyana, 2016 bahwa prevalensi gangguan menstruasi pada remaja putri dipengaruhi oleh faktor-faktor lain yang berpengaruh dalam gangguan menstruasi yaitu stress, status gizi dan aktivitas fisik, dan usia.

Menurut Atikah 2009, faktor penyebab gangguan menstruasi adalah Fungsi Hormon Terganggu yaitu Menstruasi yang berkaitan dengan sistem hormon yang diatur di otak,tepatnya pada kalenjar hipofisa. Pada sistem hormon ini akan mengirim sinyal ke indung telur untuk memproduksi.

Menurut Soekanto, 2007, menyebutkan pengalaman yang pernah dialami seseorang akan menambah pengetahuan tentang sesuatu yang berbentuk informal.

\section{SIMPULAN}

Berdasarkan hasil penelitian terhadap pengetahuan remaja putri kelas VII Tentang Menstruasi di SMP Negeri 10 Pangkalpinang, maka dapat disimpulkan bahwa 31 responden $(40,3 \%)$ pengetahuan tentang menstruasi dengan nilai baik, 37 responden $(48,1 \%)$ pengetahuan tentang siklus menstruasi dengan nilai kurang dan 51 responden $(66,2 \%)$ pengetahuan tentang gangguan menstruasi dengan nilai kurang.

\section{SARAN}

Untuk meningkatkan pengetahuan remaja tentang menstruasi perlu adanya penyuluhan tentang menstruasi pada remaja putri, juga diperlukan peran orang tua khususnya ibu di rumah sebaiknya memberikan pengetahuan dan pengalaman tentang menstruasi kepada remaja putri dan perlu peran dari guru khususnya pada mata pelajaran Biologi agar lebih menjelaskan tentang menstruasi, siklus menstruasi dan gangguan menstruasi.

\section{DAFTAR PUSTAKA}

Atikah, dkk, 2009. Menstruasi Pertama Penuh Makna. Yogyakarta : Nuha Medika.

Benson, dkk. 2009. Buku Saku Obstetri dan Ginekologi Edisi 9. Jakarta : EGC.

Djaali, 2009. Psikologi Pendidikan. Jakarta : Bumi Aksara. 
Kusmiran. 2012. Kesehatan Reproduksi Remaja dan Wanita. Jakarta : Salemba Medika

Llewellyn-Jones, Derek. 2005. Setiap Wanita. Jakarta : PT Dellapratasa Publishing, EGC

Lucyana, N, 2016, Prevalensi Kejadian Gangguan Menstruasi Berdasarkan Indeks Masa Tubuh (IMT) pada sisawa kelas VII SMP, Jurnal Kebidanan Vol.1 No. 58-64 diakses tanggal 28 Oktober 2018 melalui http://jurnal.akbiduk.ac.id/assets/doc/17 01160201069

Manuaba, IBG. 2013. Ilmu Kebidanan, Penyakit, Kandungan dan Keluarga Berencana. Jakarta : EGC.

Notoatmodjo, Soekidjo. 2003. Pendidikan dan Perilaku Kesehatan. Jakarta: PT Rineka Cipta

Notoatmodjo, Soekidjo. 2010. Promosi Kesehatan, Teori dan Aplikasinya. Jakarta : Rineka Cipta.

Prawirohardjo, 2011. Ilmu Kandungan. Jakarta : Yayasan Bina Pustaka.

Saryono, Waluyo. 2009. Sindrom Premenstruasi. Bantul : Nuha Medika.

Sukanto. 2007. Sosiologi Suatu Pengantar. Jakarta: Rajawali Press

Suyanto, dkk. 2009. Riset Kebidanan Metodologi dan Aplikasi. Jogyakarta : Mitra Cendikia Press.

Wawan, Dewi. 2010. Teori dan Pengukuran pengetahuan, Sikap dan Perilaku Manusia. Yogyakarta : Nuha Medika. 